\title{
The challenge of change: evidence, culture and expertise
}

Welcome to the October issue of Clin Med. I hope you all had a restful summer holiday and are recharged and ready for the increasing challenges that autumn and winter usually bring in our clinical practice. In addition to facing our individual, frontline issues, we collectively still face significant organisational challenges and it is unlikely, based on previous experience, that the recent proposed additional $£ 20$ billion funding settlement for the $\mathrm{NHS}$ will, on its own, be enough to provide a sustainable NHS. We are, as always, challenged to find new, more efficient and novel ways of delivering safe clinical care.

This month, Clin Med contains several research manuscripts that assess clinical initiatives that are designed to meet these challenges. It is critical that we, as experts, assess the impact of changes we make and gain the evidence to determine whether these 'good ideas' deliver the expected clinical gains in real world practice. Articles in this month's edition demonstrate that modifying the clinical delivery from face-to-face to virtual assessment for patients with long-term renal conditions appears to do this without any obvious negative impact; however, qualitative research assessing perceptions of shared care between surgeons and elderly care specialists in the management of complex older patients undergoing surgery identifies significant cultural differences and potential frictions, ${ }^{2}$ while implementation challenges of the NEWS2 score are also highlighted in patients with chronic lung disease. ${ }^{3}$ The articles in this month's Clin Med largely mirror the main themes in October $\mathrm{FHJ}$, namely systems design and sustainability, both with the articles above, and additionally with an interesting article on the challenges of a changing workforce demographic. ${ }^{4}$

As begets the title of the journal there is, as usual, a broad focus on clinical medicine with a potpourri of articles highlighting changes in the management of COPD, ${ }^{5}$ advice on modifying our language around acute kidney injury ${ }^{6}$ and a review highlighting the changing evidence around MGUS. ${ }^{7}$ There is also excellent CME on neurology offering erudite and pragmatic advice on the management of common but complex issues that we face on almost every acute medical take. Whether this is seizures, headache or functional neurological disorders these articles offer helpful expert guidance.

The acute medical care section, lessons of the month and image of the month remind us to always remain alert to the complications and side effects of usually rare or benign conditions and I hope overall this edition provides the reader with the usual interesting, informative and challenging content that we aim to provide.

Thank you to those that have taken the time to provide us with your opinions on how we should look to deliver the journals in the future and we will take these views into account as we look to develop the journal further, with the new president and senior college officers into 2019 .

\section{References}

1 Harnett $\mathrm{P}$, Jones M, Almond M, Ballasubramaniam G, Kunnath V. A virtual clinic to improve long-term outcomes in chronic kidney disease. Clin Med 2018;18:356-63.

2 Howie S, Tinker A. Are we on the same page? Exploring the role of the geriatrician in the care of the older surgical patient from the perspective of surgeons and geriatricians. Clin Med 2018;18:374-9.

3 Hodgson L, Congleton J, Venn R, Forni L, Roderick P. NEWS 2 - too little evidence to implement? Clin Med 2018;18:371-3.

4 Gordon H. Later careers - regenerating the medical workforce. Clin Med 2018;18:397-9.

5 Price O, Sarkar C, Konda S. An update on the use of inhaled therapy in COPD. Clin Med 2018;18:387-90.

6 Jones M, Tomson C. Acute kidney injury and 'nephrotoxins': mind your language. Clin Med 2018;18:384-6.

7 Atkin C, Richter A, Sapey E. What is the significance of monoclonal gammopathy of undetermined significance? Clin Med 2018;18:391-6.

Wing Commander Ed Nicol Editor-in-chief

$\begin{array}{llll}\text { Members of the editorial board } & & \\ \text { Wing Commander Edward Nicol } & \text { Prof Tahseen Chowdhury } & \text { Dr Alexandra Lake } & \text { Dr Rahul Mukherjee } \\ \text { Editor-in-chief } & \text { Dr Albert Edwards } & \text { Dr Phillip Lee } & \text { Dr Mehool Patel } \\ \text { Cono Ariti } & \text { Dr Kate Evans } & \text { Dr Tom Levett } & \text { Dr Gerrard Phillips } \\ \text { Statistical editor } & \text { Dr Johanna Feary } & \text { Prof Philip MacCarthy } & \text { Dr Roby Rakhit } \\ \text { Dr Na'eem Ahmed } & \text { Dr Maggie Hammersley } & \text { Prof Yash Mahida } & \text { Prof Phil Smith } \\ \text { Dr Michael Almond } & \text { Dr Dylan Harris } & \text { Dr Nick Manning-Cork } & \text { Dr Angela Star } \\ \text { Mr Paul Belcher } & \text { Prof Brian Hurwitz } & \text { Dr Chris Marguerie } & \text { Prof Cameron Swift } \\ \text { Prof Rodger Charlton } & \text { Dr Nicola Jones } & \text { Dr Ravik Mascarenhas } & \text { Dr Rhys Thomas } \\ \text { Dr Tim Chevassut } & \text { Dr Vikas Kapil } & \text { Prof Martin McKee } & \text { Dr Duncan Wilson } \\ & \text { Dr Chris Kirwan } & \text { Dr Andrew Medford } & \text { Dr Juliet Wright }\end{array}$

